\title{
Valorization of Lignin Side-Streams into Polyols and Rigid Polyurethane Foams-A Contribution to the Pulp and Paper Industry Biorefinery
}

\author{
João A. Pinto ${ }^{1,2}{ }^{\oplus}$, Isabel P. Fernandes ${ }^{1}\left(\mathbb{D}\right.$, Virginia D. Pinto ${ }^{1}$, Elson Gomes ${ }^{2}$, Cátia F. Oliveira ${ }^{2} \mathbb{}$, \\ Paula C. R. Pinto ${ }^{2,3}$, Luís M. R. Mesquita ${ }^{4}\left(\mathbb{D}\right.$, Paulo A. G. Piloto ${ }^{5}\left(\mathbb{D}\right.$, Alírio E. Rodrigues ${ }^{2}(\mathbb{D}$ \\ and Maria-Filomena Barreiro $1, * \mathbb{D}$
}

Citation: Pinto, J.A.; Fernandes, I.P.; Pinto, V.D.; Gomes, E.; Oliveira, C.F.; Pinto, P.C.R.; Mesquita, L.M.R.; Piloto, P.A.G.; Rodrigues, A.E.; Barreiro,

M.-F. Valorization of Lignin

Side-Streams into Polyols and Rigid

Polyurethane Foams-A

Contribution to the Pulp and Paper Industry Biorefinery. Energies 2021, 14, 3825. https://doi.org/10.3390/ en14133825

Academic Editor: Dino Musmarra

Received: 13 May 2021

Accepted: 22 June 2021

Published: 25 June 2021

Publisher's Note: MDPI stays neutral with regard to jurisdictional claims in published maps and institutional affiliations.

Copyright: (c) 2021 by the authors Licensee MDPI, Basel, Switzerland. This article is an open access article distributed under the terms and conditions of the Creative Commons Attribution (CC BY) license (https:// creativecommons.org/licenses/by/ $4.0 /)$.
1 Centro de Investigação de Montanha (CIMO), Instituto Politécnico de Bragança, Campus de Santa Apolónia, 5300-253 Bragança, Portugal; jpinto@ipb.pt (J.A.P.); ipmf@ipb.pt (I.P.F.); ginadpinto@gmail.com (V.D.P.)

2 Laboratory of Separation and Reaction Engineering (LSRE), Associate Laboratory LSRE-LCM, Department of Chemical Engineering, Faculty of Engineering of University of Porto, Rua Dr. Roberto Frias, 4200-465 Porto, Portugal; elson-gomes@bioref-colab.pt (E.G.); catia.feliz.oliveira@gmail.com (C.F.O.); paula.pinto@thenavigatorcompany.com (P.C.R.P.); arodrig@fe.up.pt (A.E.R.)

3 RAIZ—Forest and Paper Research Institute, Rua José Estevão No 221, 3800-783 Eixo, Portugal

4 Institute for Sustainability and Innovation in Structural Engineering (ISISE), Polytechnic Institute of Bragança, Campus Santa Apolónia Ap. 1134, 5300-253 Bragança, Portugal; lmesquita@ipb.pt

5 Associate Laboratory of Energy, Transports and Aeronautics-Institute of Science and Innovation in Mechanical and Industrial Engineering (LAETA-INEGI), Polytechnic Institute of Bragança,

Campus Santa Apolónia, 5300-253 Bragança, Portugal; ppiloto@ipb.pt

* Correspondence: barreiro@ipb.pt; Tel.: +35-12-7330-3089

Abstract: Valorization of industrial low-value side-streams are of great interest, contributing to boosts in the circular economy. In this context, lignin side-streams of the pulp and paper industry were oxypropylated to produce biobased polyols and tested in the synthesis of rigid polyurethane (RPU) foams. E. globulus lignins, namely a lignin isolated from an industrial Kraft black liquor and depolymerized lignins obtained as by-products of an oxidation process, were used. RPU foams, synthesized with $100 \%$ lignin-based polyols and using a $1.1 \mathrm{NCO} / \mathrm{OH}$ ratio, were characterized concerning apparent density, morphology, thermal conductivity, thermal stability, and heat release rate (HRR). Foams containing the lignin-based polyols presented densities varying from 44.7 to $112.2 \mathrm{~kg} / \mathrm{m}^{3}$ and thermal conductivity in the range of $37.2-49.0 \mathrm{~mW} / \mathrm{mK}$. For the reference foam (sample produced with $100 \%$ wt. Daltofoam TP 32015 polyol), values of $70.9 \mathrm{~kg} / \mathrm{m}^{3}$ and $41.1 \mathrm{~mW} / \mathrm{mK}$ were obtained, respectively. The achieved results point out the viability of using the generated lignin-based polyols at 100\% content in RPU foams, mainly when depolymerized lignins are used. Moreover, fire retardancy was favored when the lignin-based polyols were introduced. The proposed strategies can contribute to establishing the integrated pulp and paper biorefinery concept where material synthesis (polyols and RPU foams) can be combined with chemical production (vanillin and syringaldehyde).

Keywords: biorefinery; lignin side-streams; depolymerized lignins; lignin-based polyols; rigid polyurethane foams; flame retardant properties

\section{Introduction}

Global policies are presently directing the chemical industry towards sustainable strategies, promoting the transition to greener raw materials based on the circular economy principles and the sustainability triangle built on economic, environmental, and social pillars. The European Union (EU) Chemicals Strategy for Sustainability emphasizes developing safer and sustainable products, from the source to production, until the end of life, with materials based on renewable resources being of utmost importance [1]. Resources 
available at an industrial scale, such as low value side-streams, are of great interest under the established strategies. In this context, lignin, which is readily available from the pulp and paper industry side-streams, has received boosted interest. Lignin is available in high quantities, can be the basis of a wide range of products, and scientific investment in lignin-based processes and products is increasing [2]. One important point to take into account is the social impact of the developed processes and products [3]. An appropriated approach should consider the analysis of stakeholders' individual responses, together with their influence on the overall performance of the system [4]. In addition, this approach must be based on an appellative strategy, aiming at enhancing stakeholders' knowledge on the general socio-economic and environmental benefits of a biorefinery structure, thus increasing their interest and recognition [5]. In this perspective, lignin valorization can contribute to the implementation of the pulp and paper biorefinery concept, highlighting the relevance of carrying out this study.

Lignin, a secondary by-product of the delignification stage, is a chemically rich material, presenting as primary building blocks the p-coumaryl, coniferyl, and sinapyl alcohols linked in the aromatic structure as phenylpropanoids, namely p-hydroxyphenyl $(\mathrm{H})$, guaiacyl (G), and syringyl (S) units [6]. Traditionally, black liquor is recycled for energy production and chemicals recovering through combustion; nevertheless, valuable products can be produced from recovered lignins. This approach includes the work performed at the Laboratory of Separation and Reaction Engineering-Laboratory of Catalysis and Materials (LSRE-LCM), to produce vanillin and syringaldehyde from lignin. Briefly, the developed process comprises a first stage of lignin (or black liquor) oxidation, followed by separation and/or refining steps to obtain vanillin and syringaldehyde. From this process, a depolymerized lignin results, the valorization of which is crucial to achieve an integrated biorefinery concept [7]. This process, combined with the pulp and paper industry valorization strategy, leads to two lignin side-streams: lignin precipitated from the black liquor (isolated lignin) and depolymerized lignin derived from the oxidation process $[7,8]$. Depending on the oxidation process (batch or continuous reactor), two types of depolymerized lignins can be generated. The depolymerized lignins obtained from this process have lower molecular weight due to the imparted chemical degradation $[9,10]$.

Due to their high hydroxyl content, one of the most studied applications for lignin is rigid polyurethane (RPU) foams. They are cellular materials with low density and thermal conductivity, being widely used as insulating products [11]. Some challenges considering this application are the high sulfur content imparting the material's malodor, the low lignin solubility in the reactive mixture, the low reactivity, the high glass transition temperature $(\mathrm{Tg})$, and the high polydispersity, which can be mitigated by lignin depolymerization [12]. The used strategies for lignin incorporation comprise lignin without and with chemical modification [7]. The first approach results in the incorporation of modest lignin contents $[10,13]$. For the second one, different alternatives are available, including fractionation [14]; functionalization through reaction, e.g., with diisocyanates [15]; liquefaction to produce polyols, e.g., by oxypropylation [16-19]; or depolymerization $[10,19,20]$. Furthermore, a few recent studies have used depolymerized lignins to produce liquid polyols by oxypropylation $[10,21]$. Oxypropylation makes the hydroxyl groups, particularly the phenolic ones that are sterically hindered inside the molecule, more available for reaction. Two side reactions can occur during this process; propylene oxide (PO) homopolymerization and isomerization, favored by the presence of water and high catalyst contents. The lignin to propylene oxide ratio strongly influences the obtained polyols' characteristics, namely viscosity and hydroxyl index (IOH) [17]. To apply these products as monomers for RPU foams, their technical properties, i.e., IOH and viscosity, must be within 300-800 $\mathrm{mg} \mathrm{KOH} / \mathrm{g}$ and below $300 \mathrm{~Pa} \cdot \mathrm{s}$, respectively [16].

Conventionally, lignin-based RPU foams have improved thermal and mechanical properties [17]. Particularly, for thermal properties, this improvement depends on the maximum amount of lignin present in the formulation [21]. Beyond the lignin effect on thermal stability, it can also act as a fire-retardant agent; once under combustion, a carbona- 
ceous char coat resulting from its aromatic structure decomposition can be formed, acting as a charring layer retarding the material's combustion progression [22]. In this context, several studies have been devoted to the evaluation of lignin fire-retardant properties in RPU foams, namely when fractionated [14], as a reactive filler [13], or functionalized [15]. Lignin has been studied, e.g., in intumescent systems, as a charring agent combined with an acidic source and a blowing agent [23], or as an intumescent agent alone in biopolymer formulations other than RPU [22]. As far as it was possible to verify, no studies focused on evaluating the flame-retardant properties of lignin-based RPU foams are available in the literature. Moreover, the use of $100 \%$ lignin-based polyols produced by oxypropylation has not been reported so far, which is advantageous considering the introduced lignin content.

In this context, the present work was devoted to lignin valorization as raw material to produce polymeric materials. Lignin-based polyols were first produced by oxypropylation, then used as monomers to synthesize rigid polyurethane foams. Here, two different $E$. globulus lignins were used to produce polyols by oxypropylation-lignin isolated from the industrial Kraft liquor and depolymerized lignins (by-products of the oxidation process applied to produce vanillin and syringaldehyde). After the polyols' characterization (hydroxyl number, viscosity, and homopolymer content), the polyols were used to produce rigid polyurethane foams through a formulation comprising 100\% lignin-based polyols. After that, the foams were characterized, considering morphology, density, thermal conductivity, heat release rate (HRR), and thermal stability.

\section{Materials and Methods}

\subsection{Materials}

In this work, E. globulus lignins were used. Namely, one lignin isolated from the industrial Kraft black liquor of a Portuguese pulp and paper industry (designated by L), and three depolymerized lignins obtained as by-products of the LSRE-LCM oxidation process to produce vanillin and syringaldehyde [7] (designated by OL). These included depolymerized lignins obtained in a batch and in a continuous mode (OL-B-batch and OL-C-continuous, respectively). Additionally, the depolymerized lignin obtained from the direct oxidation of the black liquor in a continuous mode was also tested (designated by OBL-C). The reactants for the oxypropylation were potassium hydroxide (KOH) from Panreac (Darmstadt, Germany) and propylene oxide (PO) from Aldrich (Steinheim, Germany), both p.a. grade. The reactants used for polyol's characterization were of analytical grade and purchased from conventional suppliers. For the rigid polyurethane foam synthesis, the commercial polyol Daltofoam TP 32015 and the polymeric 4,4'-diphenylmethane diisocyanate (MDI) were obtained from Huntsman Polyurethanes (Pamplona, Spain). Glycerol was purchased from Scharlau (Barcelona, Spain), the NIAX Silicone SR-321, and the NIAX-A1 were supplied by Momentive Performance Materials, Inc. (La Rochette, France). The N,N-dimethyl cyclohexylamine (DMCA), and n-pentane were obtained from Sigma-Aldrich (Munich, Germany).

\subsection{Oxypropylation Reaction Conditions and Procedure}

The oxypropylation reaction was carried out in bulk using a pressure reactor Parr (model 4560) (IL, USA) of $450 \mathrm{~mL}$ capacity, equipped with a controller (model 4848) to monitor temperature, pressure, and stirring. This reactor is equipped with a reaction vessel, a heating mantle, mechanical stirrer, thermocouple, and a manometer. This enables it to work with temperatures ranging up to $350{ }^{\circ} \mathrm{C}$ and pressures up to 200 bar. To produce the polyols by oxypropylation, the desired lignin amount (dried overnight in a vacuum oven at $\left.40^{\circ} \mathrm{C}\right)$, propylene oxide $(\mathrm{PO})$, and the catalyst $(\mathrm{KOH})$ were placed into the reactor that was closed and heated under stirring until the set point temperature $\left(160{ }^{\circ} \mathrm{C}\right)$. In a typical experiment, from this initial state, the pressure and temperature start to increase progressively until a maximum value, which depends on the used amount of the catalyst and the L/PO ratio. After reaching a maximum (Pmax), the pressure decreased rapidly, 
reflecting the propylene oxide consumption. When the relative pressure reached a plateau, the reactor was cooled while being stirred, open, and the ensuing polyols were recovered.

The formulations established for the isolated lignin oxypropylation comprised $\mathrm{L} / \mathrm{PO}$ ratios $(\mathrm{g} / \mathrm{mL})$ of $20 / 80,30 / 70$, and $40 / 60$, using three catalysts levels $(1 \%, 3 \%$, and $5 \%$, lignin weight basis), e.g., the formulation 20/80/1 used a L/PO ratio of 20/80 with $1 \%$ catalyst. To produce the RPU foams, the polyols of the same series were mixed to give rise to the polyols designated by 20/80,30/70, and 40/60 ratios (e.g., the polyol 20/80 was formed by the mixture of the $20 / 80 / 1,20 / 80 / 3$, and $20 / 80 / 5$ polyols). For depolymerized lignins, only the formulation $30 / 70 / 2$ was used. Figure 1 shows a schematic representation of the polyol synthesis considering as examples the 30/70 polyol produced from the isolated lignin (L 30/70) and the 30/70 polyol produced from the OL-B lignin (OL 30/70-B).

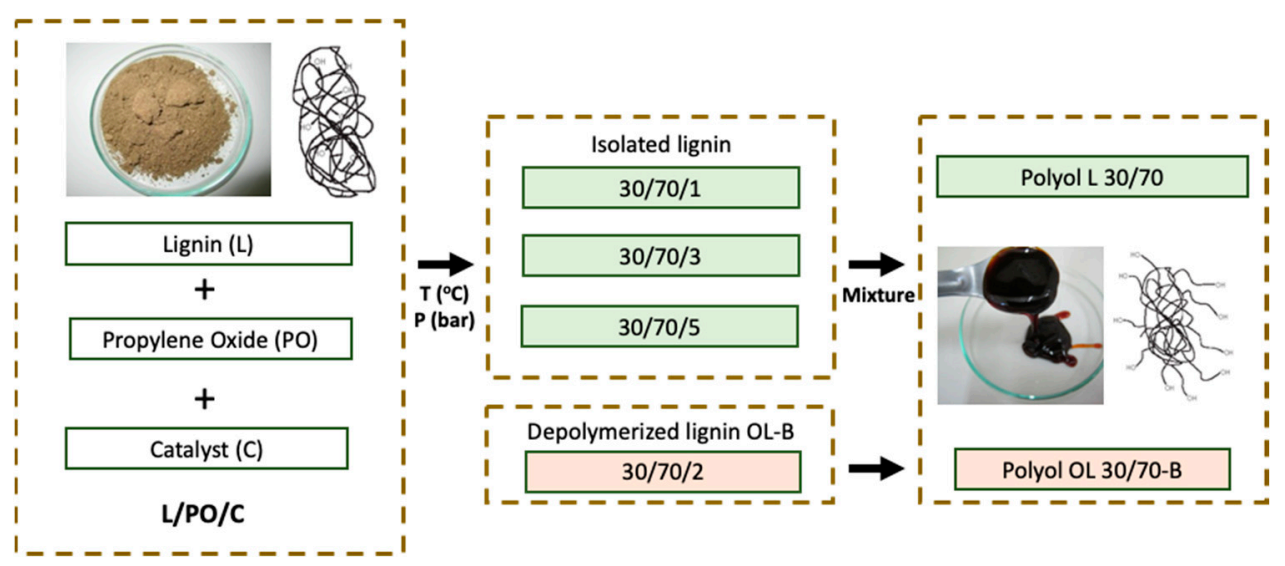

Figure 1. Schematic representation of the polyol synthesis, considering as examples the polyols $\mathrm{L}$ $30 / 70$ and the OL $30 / 70-B$.

\subsection{Lignin-Based Polyol Characterization}

The polyols were characterized in terms of hydroxyl index (IOH), homopolymer content (POO), and viscosity, following typical methodologies adopted in the group [24].

The hydroxyl index (IOH) was determined according to the ASTM D4274 standard. Briefly, the polyol ( $1 \mathrm{~g}$ ) was treated with $25 \mathrm{~mL}$ of a phthalate reagent solution (140 $\mathrm{g}$ of phthalic anhydride and $2 \mathrm{~L}$ of pyridine), being maintained under reflux for $1 \mathrm{~h}$. Afterwards, the sample solution was left to cool to room temperature, then back-titrated with $\mathrm{NaOH}$ $(0.5 \mathrm{~N})$. The titrations were carried out using an automatic titrator, TitroLine 6000, from SI Analytics (Mainz, Germany), equipped with a glass $\mathrm{pH}$ electrode.

The homopolymer (POO) content was determined by extracting twice the polyol mixture with n-hexane under reflux, following the procedure described by Pavier and Gandini [25]. The recovered fractions (oxypropylated lignin and homopolymer) were then placed in an oven under reduced pressure until a constant weight was achieved. The obtained results are expressed in $\%(w / w)$.

The viscosity was measured at $20^{\circ} \mathrm{C}$ using an Analogic Rheometer Malvern CVO 100 (Westborough, MA, USA) operating in stress-controlled mode, using a $40 \mathrm{~mm}$ diameter, $4^{\circ}$ top-angle cone plate with a gap of $150 \mu \mathrm{m}$ following a general procedure established in the group [16]. The data acquisition was made in the shear stress range of 15-3500 Pa by collecting 50 points.

\subsection{RPU Foam Production}

The RPU foams were synthesized using the one-shot free-rise method and an $\mathrm{NCO} / \mathrm{OH}$ ratio of 1.1. All the produced lignin polyols were used at a content of $100 \%$ for the RPU foam synthesis. The required amount of polyol was firstly mixed with the following additives: $10 \%$ of glycerol, $2 \%$ of surfactant (SR-321 NIAX silicone), $2 \%$ of the catalyst system (DMCHA:NIAX-A1 (50:50)), 2\% of water, and $20 \%$ of n-pentane $(\%, w / w$, based 
on the polyol weight) in the synthesis reactor for $5 \mathrm{~min}$ to homogenize the mixture. Then, the diisocyanate was added and thoroughly mixed for $10 \mathrm{~s}$. After that, the mechanical stirrer was stopped, and the foam was left to rise and cure. The foams nomenclature was established based on the used polyol name and their content, e.g., the sample 20/80/100 corresponds to the foam produced using $100 \%$ of the $20 / 80$ lignin-based polyol. For comparison purposes, a reference RPU foam was also produced using the commercial chemical system. Figure 2 shows the used reactor and the various synthesis stages.

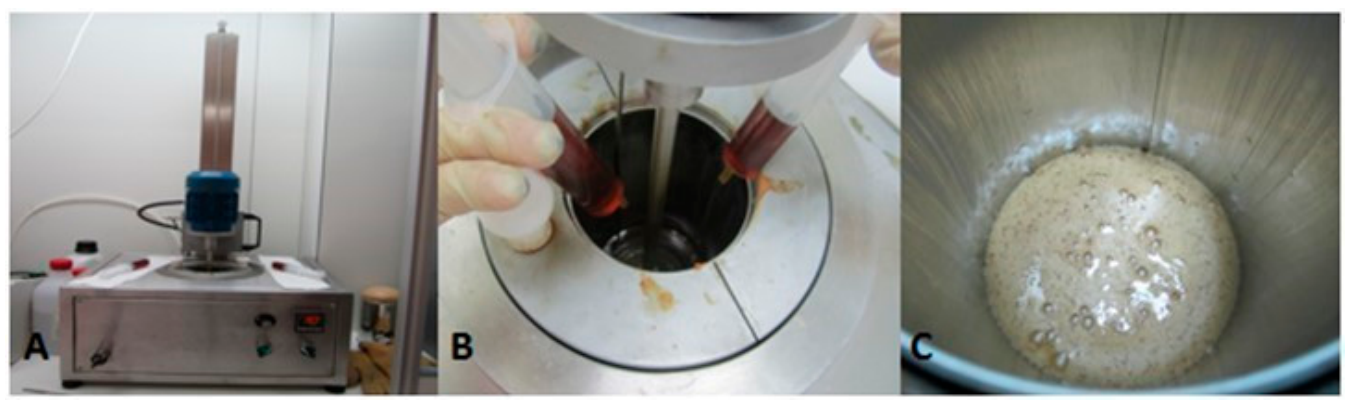

Figure 2. Stages of the RPU foam production: (A) synthesis reactor; (B) diisocyanate addition, and (C) foam rising.

\subsection{RPU Foams Characterization}

\subsubsection{Thermogravimetric Analysis}

The thermogravimetric analysis (TGA) was used to evaluate RPU foams' thermal stability. TGA analyses were carried out in a NETZSCH TG 209F3 (Selb, Germany) apparatus. The foam samples $(8-15 \mathrm{mg}$ ) were placed in alumina pans and heated at a flow rate of $10^{\circ} \mathrm{C} / \mathrm{min}$ from ambient temperature to $700{ }^{\circ} \mathrm{C}$. The analysis was performed under oxidative atmosphere (air).

\subsubsection{SEM Analysis}

The foams' cellular morphologies were analyzed using a Phenom Pro Desktop scanning electron microscope (Eindhoven, The Netherlands) using two distinct acquisition modes, BSD TOPO A and BSD Full. The samples were cut perpendicularly to the foam rising direction. The average cell diameter was estimated using the Software Phenom ProSuite by measuring 5 cells per image and using three different images per sample, acquired in the BSD Topo A acquisition mode. Images were registered using a magnification of 320X.

\subsubsection{Apparent Density Determination}

Foam density was determined by cutting circular samples with a diameter of $1.9 \mathrm{~cm}$ and $2.0 \mathrm{~cm}$ height. The samples were weighted and the apparent density obtained by calculating the ratio between the weight and the volume of each sample.

\subsubsection{Conductivity Measurements}

The thermal conductivity values of the RPU foams were evaluated through the transient plane source technique (TPS) using a Hotdisk Thermal Analyzer 2500S (Göteborg, Sweden), operating at room temperature. The isotropic standard module mode was used with a Hot Disk 5501 sensor (6.403 mm radius Kapton sensor) placed between the plane surfaces of two sample pieces. For this analysis, the RPU samples were cut in cylinders with a diameter of $1.9 \mathrm{~cm}$ and a height of $1.0 \mathrm{~cm}$. It is important to emphasize that this mode requires a perfect contact between the sensor and the sample's surface to guarantee the absence of external interference during the analysis, being imperative that both samples used as duplicates have similar dimensions. 


\subsubsection{Cone Calorimeter}

The analysis of the fire reaction behavior of the RPU foams was carried out using a mass loss cone calorimeter (Fire Testing Technology), following the general guidelines of the ISO 5660 standard. The tests were done using a radiant heat flux of $35 \mathrm{~kW} / \mathrm{m}^{2}$ for $300 \mathrm{~s}$, corresponding to $769^{\circ} \mathrm{C}$ of the equipment's electrical resistances. This apparatus is equipped with an exhaust chimney instrumented with thermocouples that, after calibration with methane gas, allows the determination of the sample's heat release rate during the thermal decomposition, with this being the heat release rate peak (pHRR) recorded for each test. The tested foam samples had $17.5 \mathrm{~mm}$ of thickness and a surface area of $74 \mathrm{~cm}^{2}$. Moreover, the time to ignition and the time to flameout were also recorded for each assay.

\section{Results and Discussion}

\subsection{Lignin-Based Polyols}

The production of lignin-based polyols was made by oxypropylation. Through this process, propylene polyoxide grafts are formed from the lignin hydroxyl groups using propylene oxide successive addition. The resultant polyol was a mixture of oxypropylated lignin and homopolymer (propylene polyoxide oligomers), a secondary product of this reaction [26]. All the produced lignin-based polyols were characterized for their technical properties, IOH, and viscosity, having in view their suitability for the application as a monomer for RPU foam synthesis (IOH between 300 and 800 and a viscosity below $300 \mathrm{~Pa} \cdot \mathrm{s})$ [16]. Besides, the homopolymer (POO) content was quantified once it remained in the polyol mixture, which were used as such, i.e., without any further purification.

Regarding the oxypropylation reaction, the maximum temperature varied from 164 to $234^{\circ} \mathrm{C}$, while the maximum pressure values ranged between 19.2 and 22.5 bar. In general, a rising trend of the maximum temperature and pressure with the incremental increase of the $\mathrm{L} / \mathrm{PO}$ oxide ratio was identified. For the $\mathrm{IOH}$, viscosity, and $\mathrm{POO}$ content, the results are presented in Table 1. Analyzing the POO content of the isolated lignin-based polyols, as the L/PO ratio increased from $20 / 80$ to $40 / 60$, the POO content decreased from $42.7 \%$ to $6.3 \%$. In contrast, the opposite occurred with the viscosity, varying from 4.8 to $221.5 \mathrm{~Pa} \cdot \mathrm{s}$, putting in evidence the effect of the POO presence on the viscosity reduction. In the case of IOH content, an increase from 302.4 to $387.7 \mathrm{mg} \mathrm{KOH} / \mathrm{g}$ was noticed due to the $\mathrm{L} / \mathrm{PO}$ ratio rise from $20 / 80$ to $40 / 60$, reflecting the effect of the lignin content increasing in the polyol formulation. For the depolymerized lignin-based polyols, the POO content varied from $10.9 \%$ to $15.9 \%$, for polyols OBL $30 / 70-\mathrm{C}$ and OL 30/70-B, with these being lower than those obtained for the isolated lignin-based polyol 30/70 (same L/PO ratio). This variation was accompanied by a viscosity variation from 134.3 to $456.5 \mathrm{~Pa} \cdot \mathrm{s}$, with these values registered for OBL 30/70-C and OL 30/70-B polyols, respectively. In addition, the $\mathrm{IOH}$ content of the depolymerized lignin polyols varied from $297.1 \mathrm{mg} \mathrm{KOH} / \mathrm{g}$ (OL 30/70-B) to $397.5 \mathrm{mg} \mathrm{KOH}$ (OBL 30/70-C), with the latter the highest IOH and viscosity amongst all the produced polyols, out of the viscosity limit suitable for RPU foam synthesis (300 Pa.s). Even though it was also tested in the foam production assays. Summarizing, the final viscosity of the resultant polyols was dependent on several factors, such as the amount of homopolymer, the amount of unreacted biomass, the extension of the grafting reaction, and the molecular structure of lignin itself, namely if it is a high-molecular-weight lignin or a depolymerized lignin (fragmented lignin). In some cases, a prevalent factor is easy to identify, but in other cases the resulting value is a combination of several factors. For the samples L 20/80, L $30 / 70$, and L $40 / 60$, the most prevalent factor was the homopolymer content, whereas for the samples OL 30/70-B and OL 30/70-C, several factors contributed. For OBL 30/70-C, the unreacted fractions perceived by naked eye inspection (not quantified) might have contributed to the observed extremely high viscosity. 
Table 1. Results of the lignin-based polyol characterization: $\mathrm{POO}, \mathrm{IOH}$ content, and viscosity.

\begin{tabular}{cccc}
\hline $\begin{array}{c}\text { Formulation } \\
(\mathbf{L} / \mathbf{P O} / \mathbf{C}, \mathbf{g} / \mathbf{m L} / \%)\end{array}$ & POO (\%, w/w) & IOH (mg KOH/g) & Viscosity $\left(\mathbf{2 0}{ }^{\circ} \mathbf{C}, \mathbf{P a} \cdot \mathbf{s}\right)$ \\
\hline L 20/80 & 42.7 & 302.4 & 4.8 \\
L 30/70 & 24.4 & 332.3 & 31.1 \\
L 40/60 & 6.3 & 387.7 & 221.5 \\
OL 30/70-B & 15.9 & 297.1 & 134.3 \\
OL 30/70-C & 16.8 & 349.8 & 169.5 \\
OBL 30/70-C & 10.9 & 397.5 & 456.5 \\
\hline
\end{tabular}

When comparing the properties of the polyols produced from the isolated lignin with the ones produced from depolymerized lignins (formulation 30/70), the main observed differences could be associated with their chemical structure dissimilarities; namely, the latter ones were lignins formed of shorter molecular fragments (they suffered chemical cleavage), lower functionality (removal of functional groups occurred during oxidation), and also molecules resulting from repolymerization reactions that might occur during the oxidation process $[10,27]$. This fact leads to fewer available sites for the propylene oxide grafting per molecule in the depolymerized lignins, as schematically represented in Figure 3. Since the number of these shorter molecules are expected to be high, more hydroxyl groups are available in total for the propylene oxide grafting, resulting in polyols with higher IOH number and lower molecular weight [21]. Comparing the lignins from batch and continuous oxidation processes, no significant differences were observed for the OL 30/70-B and OL 30/70-C polyols' properties. The OBL 30/70-C polyol (polyol obtained from the depolymerized lignin resulting from the black liquor) presented a higher $\mathrm{IOH}$ and viscosity. According to Fernandéz-Rodriguéz and coworkers [28], during the direct depolymerization of the back liquor, the extent of lignin repolymerization can reach $40 \%$, depending on the used process conditions, with this content being substantially higher than that registered for the isolated lignin oxidation. These phenomena increase the amount of larger molecules and decrease the shorter molecular chain content, leading to an increase of the generated polyol viscosity and $\mathrm{IOH}$.

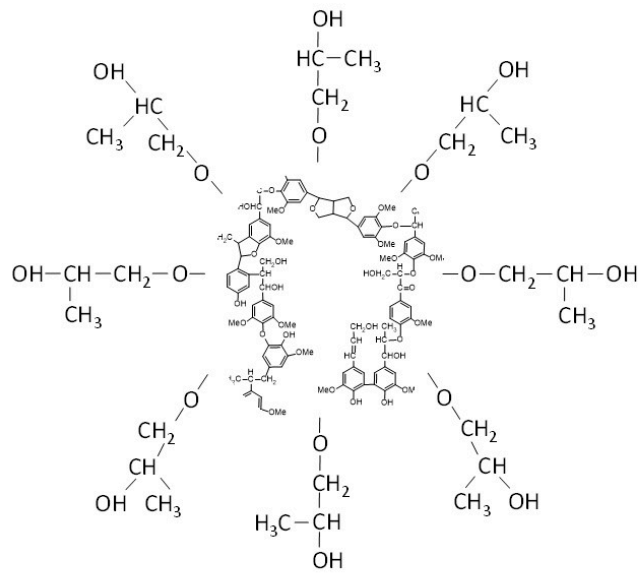

Polyols from isolated lignin

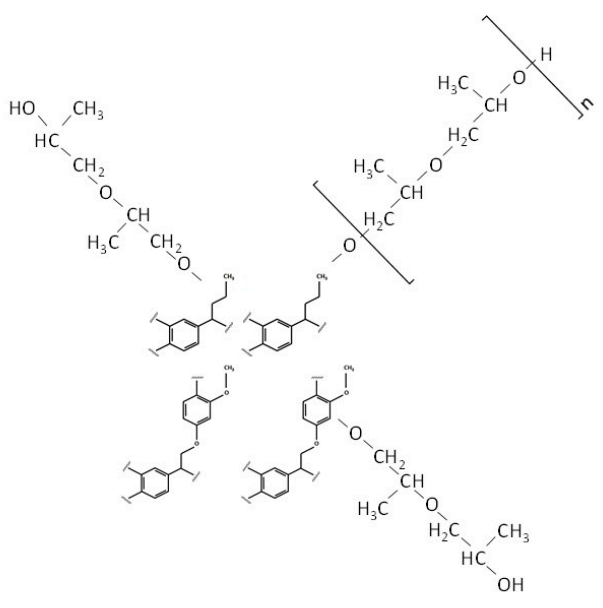

Polyols from depolymerized lignin

Figure 3. Schematic representation of the polyols' molecular chains obtained from the isolated lignin and the depolymerized lignin. 


\subsection{RPU Foam Synthesis and Characterization}

The generated polyols were successfully used to produce RPU foams at a content of $100 \%$ and the produced RPU from sample foams are shown in Figure 4.

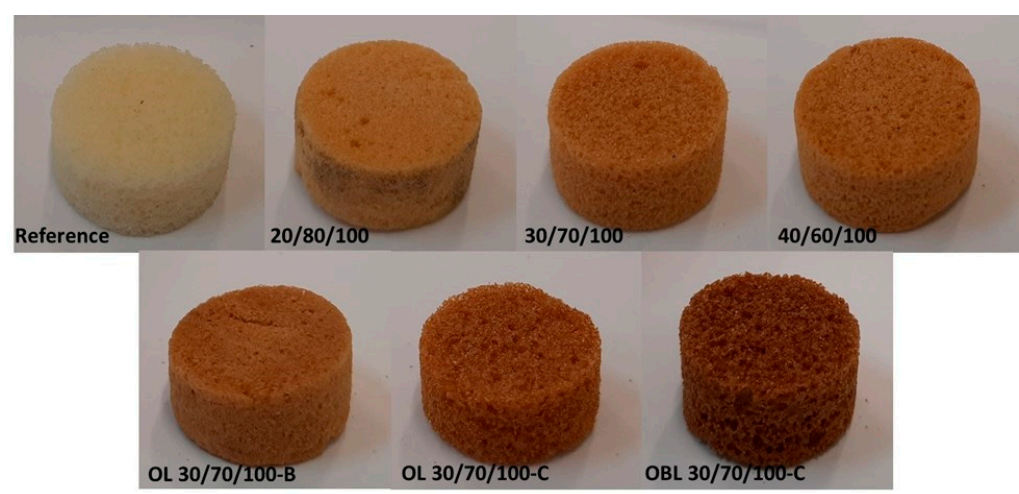

Figure 4. Samples of the produced RPU foams.

The RPU foams were characterized by evaluating the thermal stability, morphology, apparent density, thermal conductivity, and heat release rate (HRR).

The TGA and respective derivative (DTGA) profiles, evaluated under oxidative atmosphere, are shown in Figure 5. For the reference foam, two degradation stages were registered. For the first one, the degradation process started at $97^{\circ} \mathrm{C}$, and the maximum degradation temperature was $302^{\circ} \mathrm{C}$, corresponding to a weight loss of $37 \%$, which might be associated with allophanate, biuret, and urethane groups degradation, together with the polyether moieties, leading to the ultimate formation of $\mathrm{CO}_{2}$ and secondary amines [29]. For the second degradation stage, the maximum degradation temperature was $540{ }^{\circ} \mathrm{C}$ and the weight loss $59 \%$, related to the degradation of the secondary amines and other previously generated oxidation products [30]. For the isolated lignin-based polyols, a similar degradation pattern was identified, as shown in Figure 5a. The main differences related to the displacement of the two maximum degradation temperatures to lower values. In the first stage, the identified displacement was related to the removal of short molecules from the lignin-based polyol and the oxidative cleavage of some chemical bonds. This phenomenon led to the char layer formation [31], which occured together with the hard segment degradation, corresponding to a weight loss of $36 \%, 32 \%$, and $26 \%$, respectively, for the 20/80/100,30/70/100, and 40/60/100 foams. During the second stage, lignin condensation reactions, namely the ones involving aliphatic side-chains and phenolic hydroxyl groups, could occur in the presence of the $\mathrm{O}_{2}$, maintaining the formation of the char layer [32]. This char degradation happened in parallel with the oxidation of the groups generated during the hard segment decomposition and small molecule volatilization. In this stage, weight losses of $56.2 \%, 53.7 \%$, and $61.8 \%$ were registered, respectively, for the 20/80/100, 30/70/100, and 40/60/100 foams. In addition, for the lignin-based foams, the appearance of a third degradation stage above $600{ }^{\circ} \mathrm{C}$ was observed, with this being related to the char layer decomposition. Analyzing the degradation profiles shown in Figure 5 a, a displacement of this degradation peak from $613^{\circ} \mathrm{C}$ to $632^{\circ} \mathrm{C}$, as the lignin content increased, was observed. The higher degradation temperature of this stage was observed for the 40/60/100 sample, evidencing the sample's high thermal stability under oxidative atmosphere. This last degradation stage was associated with the decomposition of the char layer generated during the degradation of the lignin aromatic molecular structure [23,33]. This distinct feature highlights the positive effect of the lignin-based polyols on foam's thermal properties, particularly for the case of the highest lignin content incorporation (40/60). 


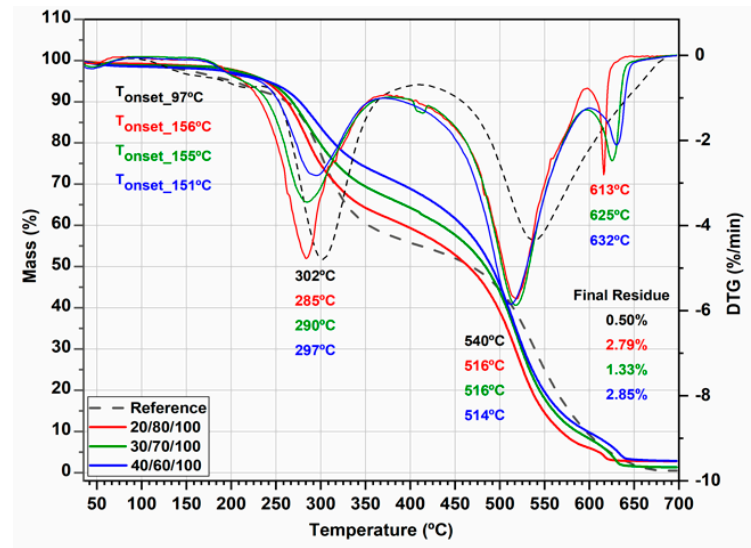

(a)

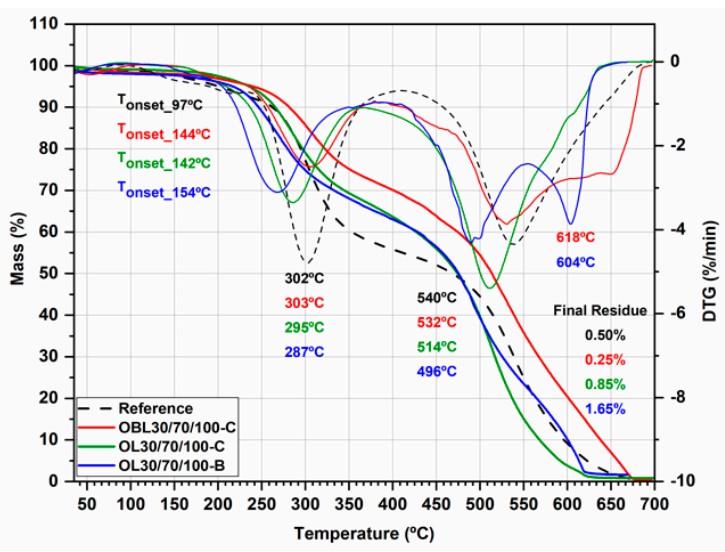

(b)

Figure 5. TGA and DTGA profiles obtained under oxidative atmosphere of: (a) reference foam and foams produced with polyols 20/80, 30/70, and 40/60; and (b) reference foam and foams produced with the depolymerized lignin polyols. $\left(\mathrm{T}_{\text {onset }}\right.$ is the initial decomposition temperature).

Regarding the thermograms of the depolymerized lignin-based foams (Figure $5 b$ ), the maximum degradation temperature of the first degradation stage was similar to those obtained from the isolated lignin-based foams, which indicates the occurrence of a decomposition pattern identical to that of the lignin-based polyols. The weight losses achieved were $27 \%, 30 \%$, and $22 \%$, respectively, for the foams OL 30/70/100-B, OL 30/70/100-C, and OBL 30/70/100-C. However, the degradation pattern at higher temperatures was different from those observed in the previous samples. For the sample OL 30/70/100-C, only a second degradation stage was registered, with a maximum degradation temperature of $514{ }^{\circ} \mathrm{C}$ and a weight loss of $65 \%$. For the OL 30/70/100-B sample, a second stage with a maximum degradation temperature of $496{ }^{\circ} \mathrm{C}$ and a weight loss of $47 \%$ was observed, together with the third stage at $604{ }^{\circ} \mathrm{C}(20 \%$ weight loss). Lastly, for the OBL $30 / 70 / 100-\mathrm{C}$ sample, a second degradation stage appeared at $532{ }^{\circ} \mathrm{C}$, with a weight loss of $65 \%$, while the third occured at $618^{\circ} \mathrm{C}$, where a weight loss of $7.15 \%$ was observed. These variations were related to the different fragments present in the depolymerized lignin molecular structure [34]. Nevertheless, looking at the depolymerized lignin-based polyols, the one obtained from the directly oxidized black liquor showed a higher capacity to generate the charring protective layer and, consequently, was a more thermally stable material. Comparatively, the isolated lignin-based polyols were closer to that observed for the 40/60 polyol, when considering the foams' thermal stability increase.

Concerning the cellular morphology of the produced foams, the SEM images are shown in Figure 6, while the average cell diameter calculated from the SEM analysis is presented in Table 2. The cellular morphology plays an important role in foams' physical and mechanical properties. In a general way, all the foams present the typical closed cellular structure. Inhomogeneous cell distribution was observed for the reference foam, characterized by large cells with some small cells distributed within. The measured average cellular diameter was $317 \mu \mathrm{m}$. In the case of the isolated lignin-based foams, the cellular distribution became more homogeneous as the lignin content increased, with a large number of small cells also noted compared with the reference sample. This observation was corroborated by the average cell diameter, which for the lignin-based foams decreased from $269 \mu \mathrm{m}$ to $216 \mu \mathrm{m}$, as the lignin content increased (20/80 to 40/60 formulation). For the depolymerized lignin-based foams, a different pattern of the cellular structure was observed, particularly for the OL 30/70/100-B sample, where larger cells were observed, contributing to a more irregular cellular distribution with an average cell diameter of $291 \mu \mathrm{m}$. For the OBL 30/70/100-C sample, the presence of defective, distorted, and larger cells was observed, characterized by an irregular cellular distribution with an average cell diameter of $252 \mu \mathrm{m}$. These modifications can be attributed to the higher viscosity of 
the OBL 30/70 polyol (456.5 Pa.s), the highest among all the produced polyols, hindering the generation and growth of the gas bubbles, and thus contributing to heterogeneous cell formation. Oppositely, the sample OL 30/70/100-C presented a homogenous cellular structure, where small cells were predominant, reflected by the lower average cell diameter of $147 \mu \mathrm{m}$. Overall, when comparing the cellular morphology of the reference foam with one of the lignin-based foams, the differences can be related with two main characteristics: the lignin content of the base polyol, the increase of which led to the increase number of small cells and a more homogenous cellular structure, and the polyols' viscosity, once viscous polyols hindered foam from rising (the generation and growth of the gas bubbles became more complex), thus leading to a distinct foam microstructure.
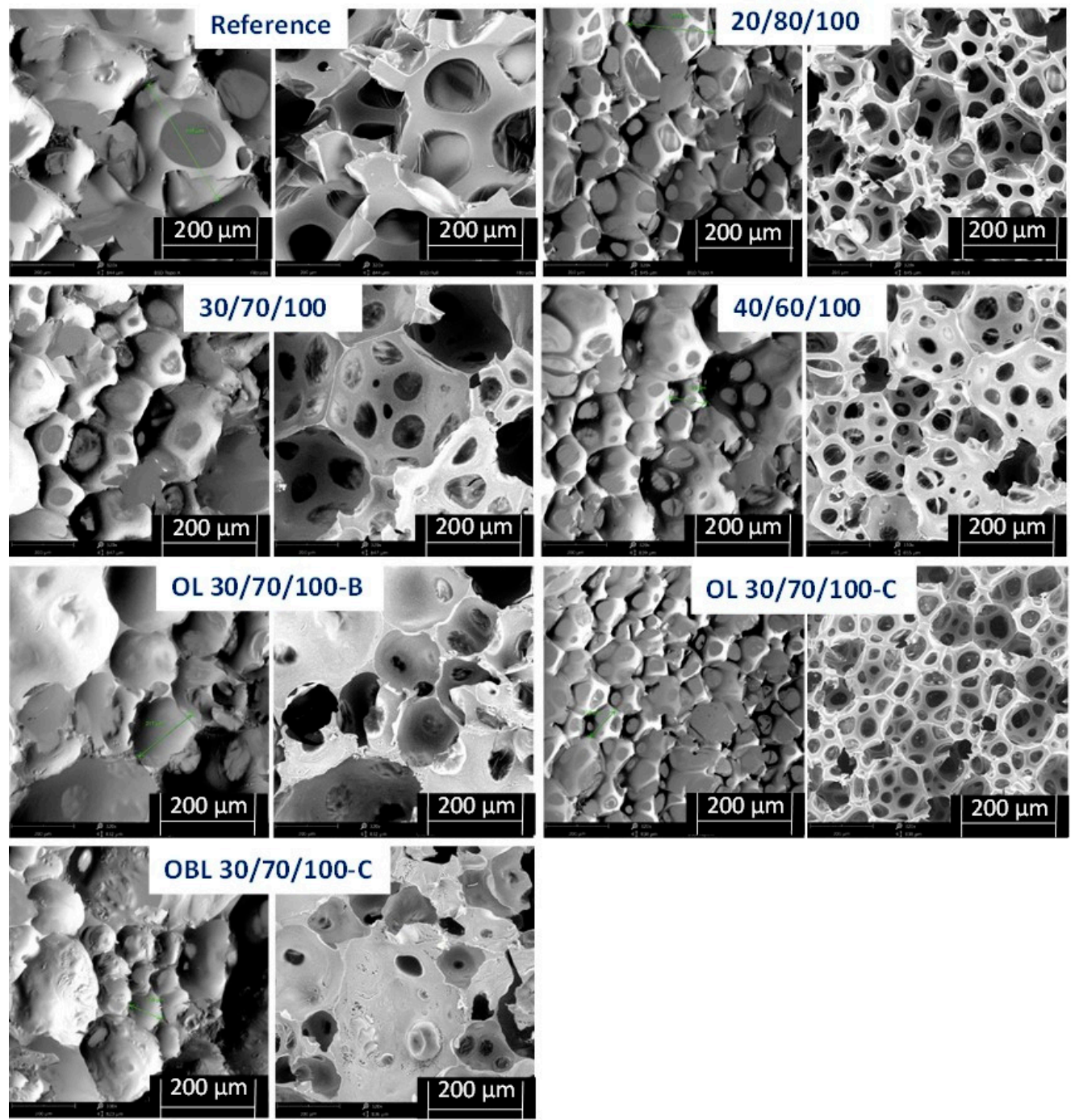

Figure 6. SEM images of the reference foam and foams produced with the lignin and depolymerized lignin polyols. For each sample, two distinct acquisition modes were used-the first image corresponds the BSD Topo A mode, while the second one corresponds to BSD Full mode.

The obtained results of apparent density are presented in Table 2. The apparent density is closely related to the cellular structure of the foams [14]. The registered values for the lignin-based foams varied between 45 and $112.2 \mathrm{Kg} / \mathrm{m}^{3}$, while for the reference sample a density of $70.9 \mathrm{Kg} / \mathrm{m}^{3}$ was obtained. In general, increasing the lignin content in the foam formulation led to an increased foam density, namely to 44.7 and $54.0 \mathrm{Kg} / \mathrm{m}^{3}$ for the samples 20/80/100 and 30/70/100, respectively. The sample 40/60/100 had a density of $71.7 \mathrm{Kg} / \mathrm{m}^{3}$, closer to the reference foam. For the depolymerized lignin-based 
foams, the density values varied from $46.8 \mathrm{Kg} / \mathrm{m}^{3}$ (OL $30 / 70 / 100-\mathrm{C}$ ) to $112.2 \mathrm{Kg} / \mathrm{m}^{3}$ (OBL $30 / 70 / 100-C)$. This difference evidences the effect of the cellular structure once the OL 30/70/100-C foam had a homogenous cellular structure with a higher number of smallsized cells. In comparison, the OBL 30/10/100-C comprised larger cells and an irregular cell-size distribution.

Table 2. Results of the average cell diameter, apparent density, and thermal conductivity of the RPU foams.

\begin{tabular}{cccc}
\hline Formulation & $\begin{array}{c}\text { Average Cell } \\
\text { Diameter }(\boldsymbol{\mu \mathbf { m } )}\end{array}$ & $\begin{array}{c}\text { Apparent Density } \\
\left(\mathbf{K g} / \mathbf{m}^{\mathbf{3}}\right)\end{array}$ & $\begin{array}{c}\text { Thermal Conductivity } \\
(\mathbf{m W / m K})\end{array}$ \\
\hline $20 / 80 / 100$ & $269 \pm 49$ & 44.7 & 37.2 \\
$30 / 70 / 100$ & $274 \pm 50$ & 54.0 & 39.9 \\
$40 / 60 / 100$ & $216 \pm 75$ & 71.7 & 40.1 \\
OL 30/70/100-B & $291 \pm 107$ & 81.3 & 44.6 \\
OL 30/70/100-C & $147 \pm 28$ & 46.8 & 38.5 \\
OBL 30/70/100-C & $252 \pm 92$ & 112.2 & 49.0 \\
Reference foam & $317 \pm 98$ & 70.9 & 41.1 \\
\hline
\end{tabular}

Regarding the thermal conductivity, low values guarantee a low heat transfer capacity, thus diminishing the heat losses [15]. In addition, the thermal conductivity is strongly related to the foams' cellular structure, and hence, with the foams' apparent density [14]. Generally, the lignin-based foams presented lower thermal conductivity values than the reference $(41.1 \mathrm{~mW} / \mathrm{mK})$ (Table 2). The main exceptions were the foams produced with depolymerized lignin polyols, OBL 30/70/100-C (49.0 mW/mK) and OL 30/70/100-B $(44.6 \mathrm{~mW} / \mathrm{mK})$, which had higher densities but a more irregular cellular distribution. To highlight that, all the foams produced with lignin-based polyols had a thermal conductivity lower than the reference foam, providing evidence of the positive effect of these polyols on the foam's thermal properties. The OL 30/70/100-C foam presented a thermal conductivity of $38.5 \mathrm{~mW} / \mathrm{mK}$, with this being the lowest value registered among the produced depolymerized lignin-based foams. In summary, for OL 30/70/100-B and OL 30/70/100-C, the most prevalent factor affecting density and thermal conductivity was the reactivity of the polyols, translated by the respective IOH number. For the OBL 30/70-100 foam, the sample produced with the OBL 30/70-C polyol, which presented the highest viscosity, this parameter dictated the foam's properties. This analysis is in good agreement with the findings of Li and co-workers [15], who critically analyzed the different patterns of foams' cellular structures based on the polyols' properties.

The results obtained for the heat release rate (HHR) measured during the foams' combustion are shown in Figure $7 \mathrm{a}$ for the isolated lignin-based foams and in Figure $7 \mathrm{~b}$ for the depolymerized lignin-based foams. Regarding the properties described in Table 3, the ignition time was an important parameter to take into account. It corresponds to the time required for the sample surface to attain the flaming combustion, with this being considered an intrinsic material property, depending on both the sample thickness and the material characteristics [35]. Analyzing the time to ignition registered in cone calorimeter test, a variation between 2.0 (samples 20/80/100, 40/60/100, and OL 30/70/100-C) and $7.0 \mathrm{~s}$ (OLB 30/70/100 sample) was observed. The highest value was obtained for the OBL $30 / 70 / 100-C$ sample. For the reference foam, the time to ignition was $3.0 \mathrm{~s}$. These results point out an improved behavior conferred by the depolymerized lignins, specifically for the OBL 30/70/100-C foam under the tested conditions once its combustion initiation was delayed compared with the reference foam. 


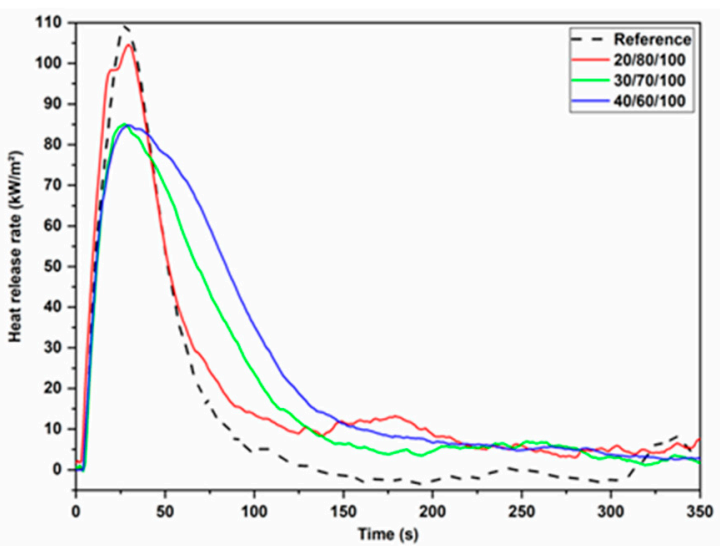

(a)

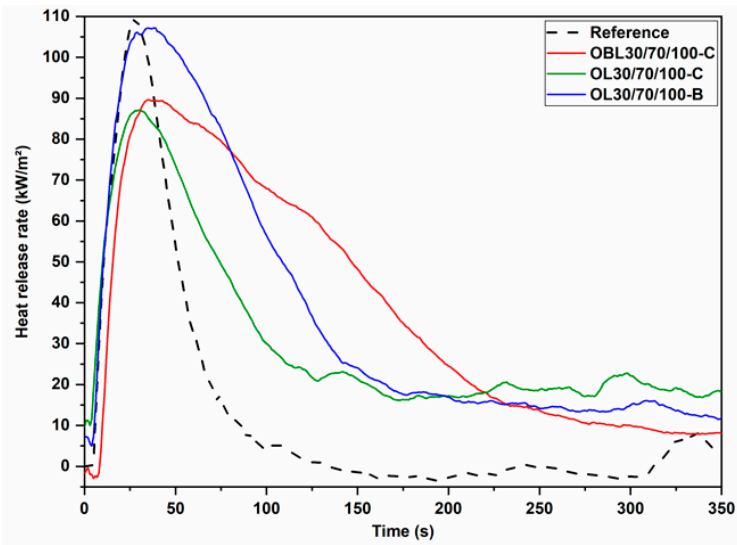

(b)

Figure 7. Heat release rate of (a) reference foam and foams produced with the lignin polyols, and (b) reference and foams produced with the depolymerized lignin polyols.

Table 3. Values of the peak of heat release rate, time to ignition, and time to flameout of the tested RPU foams.

\begin{tabular}{cccc}
\hline Formulation & Time to Ignition (s) & Time to Flameout (s) & pHRR (kW/m $\left.\mathbf{m}^{2}\right)$ \\
\hline 20/80/100 & 2.0 & 47.0 & 104.5 \\
$30 / 70 / 100$ & 4.0 & 106.0 & 85.1 \\
$40 / 60 / 100$ & 2.0 & 122.0 & 84.8 \\
OL 30/70/100-B & 3.0 & 134.0 & 107.2 \\
OL 30/70/100-C & 2.0 & 105.0 & 87.1 \\
OLB 30/70/100-C & 7.0 & 244.0 & 89.7 \\
Reference foam & 3.0 & 60.0 & 109.1 \\
\hline
\end{tabular}

The highest pHHR value amongst all the tested foams was $109.1 \mathrm{~kW} / \mathrm{m}^{2}$, obtained for the reference sample. In addition, the fast ignition associated with the intense fire growth represented by the sharp peak of the heat release rate graphic (Figure 7) corresponded to the typical behavior of cellular materials when subjected to a combustion process [35]. After the pHHR of the reference, the highest values were 107.2 and $104.5 \mathrm{~kW} / \mathrm{m}^{2}$, with these being registered for the OL-30/70/100-B and 20/80/100 samples, respectively. Oppositely, the lowest pHHR value was $84.8 \mathrm{~kW} / \mathrm{m}^{2}$, obtained for the $40 / 60 / 100$ sample. Thus, in general, the lignin-based foams had a lower heat release rate when compared with the reference sample.

The elapsed time between the ignition and the pHHR (maximum of the HHR curves), shown in Figure $7 \mathrm{a}, \mathrm{b}$, can be related to the flame propagation rate, meaning that more sharp peaks are associated with faster combustion processes when conjugated with lower flame out times [23]. This behavior was observed both on the HHR curves of the reference and the 20/80/100 foams (Figure 7a). An entirely different pattern was noticed for the $30 / 70 / 100$ and 40/60/100 HRR profiles. A similar time interval between the ignition and the pHHR was registered, with the flame out times being longer, varying from 106 to $122 \mathrm{~s}$, thus reflecting a slower combustion process. For the depolymerized lignin-based foams (Figure $7 \mathrm{~b}$ ), the longer time interval between the ignition and pHHR was observed for the OBL 30/70/100-C sample. In addition, this foam presented the highest flameout time amongst all the produced samples. This fact can be partially attributed to the higher apparent density of this foam [35].

For the cone calorimeter tests, and in comparison with the reference foam, the 40/60/100 foam presented the best performance under the used conditions. Besides, this lignin-based foam had values of apparent density and thermal conductivity closer to the reference. The low HRR points out a high fire resistance, which can be attributed to this 
polyol's high lignin content, among all the produced ones. Lignin is widely referred to as presenting fire-retardant properties. Under combustion, it forms a carbonaceous char layer due to its aromatic structure decomposition, acting as an insulating layer and retarding the material's combustion progression [22]. This fact is shown by different studies devoted to the production and characterization of RPU foams based on functionalized lignin [11,15] and lignin use as filler [13], with a similar role expected for foams produced using $100 \%$ of lignin-based polyols. Furthermore, the overall results show the decreasing of the HRR for the formulations incorporating lignin, especially for those based on the depolymerized fractions resulting from the continuous oxidation process.

\section{Conclusions}

The present study was focused on the synthesis of lignin-based polyols through oxypropylation. The main focus was to show the viability of using the produced ligninbased polyols, particularly the ones derived from depolymerized lignins, and their impact on conductivity (a relevant parameter for RPU foams that are mostly used as insulating materials), and fire retardancy (an added value for these materials that can be imparted by lignin itself). Complementary studies, namely mechanical characterization of the produced RPU foams are still needed and are foreseen as future work. Two types of E. globulus lignins were used. One addressed the isolated lignin from the black liquor, and the other depolymerized lignins, a by-product of an oxidative process. Thereafter, these polyols were successfully employed for RPU foam production at a content of $100 \%$. The foams' apparent densities varied from 45 to $112.2 \mathrm{~kg} / \mathrm{m}^{3}$, with the foams containing the lignin-based polyols presenting a thermal conductivity lower than the one of the reference foam. In addition, the pHHR of the lignin-based foams decreased with the lignin content increase, with the best results achieved for the 40/60/100 foam. From an overall analysis, it can be concluded that the produced lignin-based polyols can be used at a content of $100 \%$, results not reported so far, to produce RPU foams with properties similar to the ones of the reference sample. In addition, the obtained results of the cone calorimeter tests provided evidence of the positive effect of the lignin-based polyol incorporation. Higher lignin contents contribute to the improvement of the fire retardancy properties. Based on the overall results, it was proved that the depolymerized lignins generated during the oxidation process to produce vanillin and syringaldehyde, particularly the ones obtained in the continuous reactor, can be further valued for polymeric materials production. Overall, the valorization of the low value side-streams, in this case lignin, can bring added value to the implementation of the pulp and paper biorefinery concept to which this work was a contribution.

Author Contributions: Conceptualization, P.C.R.P., A.E.R. and M.-F.B. methodology, P.C.R.P., L.M.R.M., P.A.G.P., A.E.R. and M.-F.B.; investigation, J.A.P., V.D.P., I.P.F., E.G. and C.F.O.; writing-original draft preparation, J.A.P. and I.P.F.; writing - review and editing, L.M.R.M., P.A.G.P., A.E.R. and M.-F.B.; supervision, A.E.R. and M.-F.B.; funding acquisition, P.C.R.P., A.E.R. and M.-F.B. All authors have read and agreed to the published version of the manuscript.

Funding: Foundation for Science and Technology (FCT, Portugal) and FEDER under Program PT2020 for financial support to CIMO (UIDB/00690/2020), and to UIDB/50020/2020 of the Associate Laboratory LSRE-LCM - funded by national funds through FCT/MCTES (PIDDAC); national funding by FCT, PI, through the institutional scientific employment program contract for Isabel P. Fernandes. This work was carried out under the Project No. 33969 Bioblocks-Design of biobased products from renewable lignocellulosic sources as precursors for the bioindustry of chemical synthesis and biomaterials-financed by FEDER through the Operational Program for Competitiveness Factors (POFC) and QREN. To COST Action LignoCOST (CA17128) supported by COST (European Cooperation in Science and Technology).

Data Availability Statement: Not applicable.

Conflicts of Interest: The authors declare no conflict of interest. 


\section{References}

1. European Commission Green Deal: Commission Adopts New Chemicals Strategy towards a Toxic-Free Environment. 2020. Available online: https:/ / ec.europa.eu/info/strategy/priorities-2019-2024/european-green-deal_en (accessed on 8 January 2021).

2. Garlapati, V.K.; Chandel, A.K.; Kumar, S.J.; Sharma, S.; Sevda, S.; Ingle, A.P.; Pant, D. Circular economy aspects of lignin: Towards a lignocellulose biorefinery. Renew. Sustain. Energy Rev. 2020, 130, 109977. [CrossRef]

3. Cadena, E.; Rocca, F.; Gutierrez, J.A.; Carvalho, A. Social life cycle assessment methodology for evaluating production process design: Biorefinery case study. J. Clean. Prod. 2019, 238, 117718. [CrossRef]

4. Leibensperger, C.; Yang, P.; Zhao, Q.; Wei, S.; Cai, X. The synergy between stakeholders for cellulosic biofuel development: Perspectives, opportunities, and barriers. Renew. Sustain. Energy Rev. 2021, 137, 110613. [CrossRef]

5. Falcone, P.M. Analysing stakeholders' perspectives towards a socio-technical change: The energy transition journey in Gela Municipality. AIMS Energy 2018, 6, 645-657. [CrossRef]

6. Glasser, W.G. About Making Lignin Great Again-Some Lessons from the Past. Front. Chem. 2019, 7, 565. [CrossRef] [PubMed]

7. Rodrigues, A.E.; Pinto, P.C.D.O.R.; Barreiro, M.F.; Da Costa, C.A.E.; Da Mota, M.I.F.; Fernandes, I. An Integrated Approach for Added-Value Products from Lignocellulosic Biorefineries. In An Integrated Approach for Added-Value Products from Lignocellulosic Biorefineries; Springer International Publishing: Cham, Switzerland, 2018.

8. da Silva, E.B.; Zabkova, M.; Araújo, J.; Cateto, C.; Barreiro, M.; Belgacem, M.; Rodrigues, A. An integrated process to produce vanillin and lignin-based polyurethanes from Kraft lignin. Chem. Eng. Res. Des. 2009, 87, 1276-1292. [CrossRef]

9. Ma, C.; Mei, X.; Fan, Y.; Zhang, Z. Oxidative Depolymerizaton of Kraft Lignin and its Application in the Synthesis of Ligninphenol- formaldehyde Resin. Bioresources 2017, 13, 1223-1234. [CrossRef]

10. Mahmood, N.; Yuan, Z.; Schmidt, J.; Tymchyshyn, M.; Xu, C.C. Hydrolytic liquefaction of hydrolysis lignin for the preparation of bio-based rigid polyurethane foam. Green Chem. 2016, 18, 2385-2398. [CrossRef]

11. Zhang, X.; Kim, Y.; Eberhardt, T.L.; Shmulsky, R. Lab-scale structural insulated panels with lignin-incorporated rigid polyurethane foams as core. Ind. Crop. Prod. 2019, 132, 292-300. [CrossRef]

12. Alinejad, M.; Henry, C.; Nikafshar, S.; Gondaliya, A.; Bagheri, S.; Chen, N.; Singh, S.K.; Hodge, D.B.; Nejad, M. Lignin-Based Polyurethanes: Opportunities for Bio-Based Foams, Elastomers, Coatings and Adhesives. Polymers 2019, 11, 1202. [CrossRef]

13. Luo, S.; Gao, L.; Guo, W. Effect of incorporation of lignin as bio-polyol on the performance of rigid lightweight wood-polyurethane composite foams. J. Wood Sci. 2020, 66, 66. [CrossRef]

14. Li, B.; Zhou, M.; Huo, W.; Cai, D.; Qin, P.; Cao, H.; Tan, T. Fractionation and oxypropylation of corn-stover lignin for the production of biobased rigid polyurethane foam. Ind. Crop. Prod. 2020, 143, 111887. [CrossRef]

15. Zhang, X.; Jeremic, D.; Kim, Y.; Street, J.; Shmulsky, R. Effects of Surface Functionalization of Lignin on Synthesis and Properties of Rigid Bio-Based Polyurethanes Foams. Polymers 2018, 10, 706. [CrossRef] [PubMed]

16. Cateto, C.A.; Barreiro, M.F.; Rodrigues, A.E.; Belgacem, M.N. Optimization Study of Lignin Oxypropylation in View of the Preparation of Polyurethane Rigid Foams. Ind. Eng. Chem. Res. 2009, 48, 2583-2589. [CrossRef]

17. Li, Y.; Ragauskas, A. Kraft Lignin-Based Rigid Polyurethane Foam. J. Wood Chem. Technol. 2012, 32, 210-224. [CrossRef]

18. Kurańska, M.; Pinto, J.; Salach, K.; Barreiro, M.; Prociak, A. Synthesis of thermal insulating polyurethane foams from lignin and rapeseed based polyols: A comparative study. Ind. Crop. Prod. 2020, 143, 111882. [CrossRef]

19. Abid, A.; Brosse, N.; Ziegler-Devin, I.; Gabsi, S. Production and characterization of rigid polyurethane foam by oxypropylation of organosolv lignin extracted from exhausted olive pomace. J. Polym. Res. 2020, 27, 1-7. [CrossRef]

20. Mahmood, N.; Yuan, Z.; Schmidt, J.; Xu, C.C. Preparation of bio-based rigid polyurethane foam using hydrolytically depolymerized Kraft lignin via direct replacement or oxypropylation. Eur. Polym. J. 2015, 68, 1-9. [CrossRef]

21. Ihalainen, P.; Antunes, J.; Levée, T. Application of Enzymatically Treated Lignin Oligomers as Lignopolyols For A Full Replacement of Commercial Polyols in Polyurethane Foam Formulation. Biomed. J. Sci. Tech. Res. 2019, 24, 17898-17904. [CrossRef]

22. Mandlekar, N.; Cayla, A.; Rault, F.; Giraud, S.; Salaün, F.; Malucelli, G.; Guan, J.-P. An Overview on the Use of Lignin and Its Derivatives in Fire Retardant Polymer Systems. In Lignin-Trends and Applications; Poletto, M., Ed.; IntechOpen: London, UK, 2018; Volume 32, pp. 137-144.

23. Lu, W.; Li, Q.; Zhang, Y.; Yu, H.; Hirose, S.; Hatakeyama, H.; Matsumoto, Y.; Jin, Z. Lignosulfonate/APP IFR and its flame retardancy in lignosulfonate-based rigid polyurethane foams. J. Wood Sci. 2018, 64, 287-293. [CrossRef]

24. De Rezende, S.C.; Jo, A.P.; Fernandes, I.P.; Barreiro, F.V.L.A.M.-F. Oxypropylation of Brazilian Pine-Fruit Shell Evaluated by Principal Component Analysis. J. Renew. Mater. 2018, 6, 715-723. [CrossRef]

25. Pavier, C.; Gandini, A. Oxypropylation of sugar beet pulp. 1. Optimisation of the reaction. Ind. Crop. Prod. 2000, 12, 1-8. [CrossRef]

26. Pinto, J.A.; Prieto, M.A.; Ferreira, I.C.; Belgacem, M.N.; Rodrigues, A.E.; Barreiro, M.F. Analysis of the oxypropylation process of a lignocellulosic material, almond shell, using the response surface methodology (RSM). Ind. Crop. Prod. 2020, 153, 112542. [CrossRef]

27. Klapiszewski, Ł.; Szalaty, T.J.; Jesionowski, T. Depolymerization and Activation of Lignin: Current State of Knowledge and Perspectives. In Lignin-Trends and Applications; IntechOpen: London, UK, 2018; pp. 1-27.

28. Fernández-Rodríguez, J.; Erdocia, X.; De Hoyos, P.L.; Alriols, M.G.; Labidi, J. Small phenolic compounds production from Kraft black liquor by lignin depolymerization with different catalytic agents. Chem. Eng. Trans. 2017, 57, $133-138$. 
29. Zia, K.M.; Bhatti, H.N.; Bhatti, I.A. Methods for polyurethane and polyurethane composites, recycling and recovery: A review. React. Funct. Polym. 2007, 67, 675-692. [CrossRef]

30. He, J.-J.; Jiang, L.; Sun, J.-H.; Lo, S.M. Thermal degradation study of pure rigid polyurethane in oxidative and non-oxidative atmospheres. J. Anal. Appl. Pyrolysis 2016, 120, 269-283. [CrossRef]

31. Brebu, M.; Vasile, C. Thermal degradation of lignin-A review. Cellul. Chem. Technol. 2010, 44, 353-363.

32. Hirose, S.; Kobashigawa, K.; Izuta, Y.; Hatakeyama, H. Thermal degradation of polyurethanes containing lignin studied by TG-FTIR. Polym. Int. 1998, 47, 247-256. [CrossRef]

33. Shen, D.; Hu, J.; Xiao, R.; Zhang, H.; Li, S.; Gu, S. Online evolved gas analysis by Thermogravimetric-Mass Spectroscopy for thermal decomposition of biomass and its components under different atmospheres: Part I. Lignin. Bioresour. Technol. 2013, 130, 449-456. [CrossRef]

34. Ahmad, Z.; Al Dajani, W.W.; Paleologou, M.; Xu, C.C. Sustainable Process for the Depolymerization/Oxidation of Softwood and Hardwood Kraft Lignins Using Hydrogen Peroxide under Ambient Conditions. Molecules 2020, 25, 2329. [CrossRef]

35. Schartel, B.; Hull, T.R. Development of fire-retarded materials-Interpretation of cone calorimeter data. Fire Mater. 2007, 31, 327-354. [CrossRef] 